This is a self-archived version of an original article. This version may differ from the original in pagination and typographic details.

Author(s): Mustola, Marleena

Title: Why is a live chicken banned from the kindergarten? : Two lessons learned from teaching posthuman pedagogy to university students

Year: 2019

Version: Accepted version (Final draft)

Copyright: ㄷ 2019 Philosophy of Education Society of Australasia

Rights: In Copyright

Rights url: http://rightsstatements.org/page/InC/1.0/?language=en

Please cite the original version:

Mustola, M. (2019). Why is a live chicken banned from the kindergarten? : Two lessons learned from teaching posthuman pedagogy to university students. Educational Philosophy and Theory, 51(14), 1434-1443. https://doi.org/10.1080/00131857.2018.1553712 


\title{
Why Is a Live Chicken Banned from Kindergarten? \\ Two Lessons Learned from Teaching Posthuman Pedagogy to University \\ Students
}

Marleena Mustola

\begin{abstract}
The hierarchical human-centric paradigm has been criticized by various movements of posthuman philosophy because this paradigm forgets and dismisses nonhuman beings and entities: animals, nature, objects, and technology. When I developed a course called 'Education and Adaptations of Animal Studies' for university students in 2015, I learned two lessons in practice. First, many humans, pedagogues, and academics want to hold on to their anthropocentric worldview that separates them from other species. Second, in pedagogical practices humans prefer to avoid confronting the violence they do toward animals. In this paper, I reflect on these two lessons learned and consider what they tell us about the dichotomies, anthropocentrism, and speciesism visible in pedagogical practices. I also discuss how posthuman pedagogy and posthuman ethics can help us ask uneasy questions that fracture the uncertain conception of human superiority.
\end{abstract}

Keywords: posthuman pedagogy, animals, humans, anthropocentrism, speciesism, ethics 
I became immersed in posthuman philosophy purely by accident. In 2015 , I was a visiting scholar at the Pennsylvania State University, US, doing research on childhood studies and art education, but on my days off, I worked as a volunteer at the local animal rescue shelter. As I tried to convince one more tiny feline hissing in a corner that there was nothing to be afraid of, I became, mainly nonacademically, interested in stray cats' misbehavior. This led me to read an intriguing, popular nonfiction book by Laurel Braitman called Animal Madness: How Anxious Dogs, Compulsive Parrots, and Elephants in Recovery Help Us Understand Ourselves (2014), and I realized that people diagnose mental illnesses for nonhuman animals in an anthropocentric manner. It also hit me that humans and nonhuman animals share profound similarities. I started to Google. Not too late, I found posthuman philosophy and began to comprehend how positing humans above other animals, nature, and matter (Grusin, 2015; Wolfe, 2009) constructs the anthropocentric way we understand the world.

Posthumanism is a concept that covers various movements, schools of thought, theories, philosophies, and methodologies. Usually, the term is used as an umbrella term, or alternatively, the concepts 'posthuman,' 'posthuman turn,' or 'nonhuman turn'1 are used somewhat analogously (Ferrando, 2013; Grusin, 2015; Wolfe, 2009). Movements such as transhumanism, new materialism, object-oriented ontology, speculative realism, actor-network theory, and assemblage theory, to name just a few, may be located within the diverse theoretical and philosophical field that forms what we understand as posthumanism. These various movements position themselves or can be positioned as " "post" to the concept of the human and to the historical occurrence of humanism, both based [--] on hierarchical social constructs and humancentric assumptions' (Ferrando, 2013, p. 29). In this paper, posthumanism is defined similarly with Ferrando's description: Posthumanism refers to various philosophical and theoretical approaches that strive to detach themselves from the anthropocentric worldview fetishizing humans. Posthuman pedagogy, in turn, is used here to

\footnotetext{
${ }^{1}$ Unlike the posthuman turn, the nonhuman turn does not make assumptions that humans have progressed from human to posthuman (Grusin, 2015, p. ix).
} 
describe the pedagogical practices and ideas that are found in posthuman thinking. Directing attention to other beings and entities on our planet can offer alternatives for student-centered pedagogy (Chiew, 2016) that represents current individualistic culture.

After leaving US and returning to Finland, I decided that I wanted to continue my journey with posthuman philosophy as a researcher and pedagogue, and to create an academic course concerning the subject. Combining posthuman philosophy with childhood studies is quite easy, and the opportunities for research topics seem endless ${ }^{2}$ (Mustola, 2018; Rautio, 2013), but choosing the course topic caused me more trouble. I work in the Department of Education at the University of Jyväskylä. Thus, the course had to have something to do with education. Because my interest in posthuman philosophy originated from my interest in animals, I came up with the tentative course title 'Education and Adaptations of Animal Studies' and created a syllabus that asked: 'What can we learn from nonhuman animals about education?' To begin, I thought about how the educational methods applied to humans and nonhuman animals have similarities, visible in the current popular culture, such as in the reality TV shows 'Supernanny' and 'My Cat from Hell.' I also thought about how animal testing in psychology and educational sciences has profoundly affected current thought and research on education. The literature review addressed that there are numerous scientific articles in which education and animals are by some means linked. There is, for instance, research on the participation of children with disabilities and animals in society (Donaldson \& Kymlicka, 2016), on parenting babyfied dogs and treating dogs as 'furry children' (Power, 2008; Vänskä, 2014), on dogs' human-like behavior (Wynne, Dorey, \& Udell, 2011), on the animal/human divide in pet-keeping (Fox, 2006), on orangutans playing digital games (Wirman, 2014), on children's relationships with animals (DeLoache, Pickard, \& LoBue, 2011), on animal-assisted therapies (Kazdin, 2011), and more broadly on human-animal interaction (Abell, 2013; Amiot \& Bastian, 2015; Palmer, Malone, \& Park, 2015).

\footnotetext{
${ }^{2}$ There are also some research networks and projects specifically focused on childhood and animals; see, for instance, the Common Worlds Research Collective, http://commonworlds.net/.
} 
The outset seemed promising. Thus, I started to ask colleagues to lecture during the course. Some were enthusiastic, but to be honest, some were plainly resentful. In this paper, I focus on the two most important lessons I learned while developing and teaching this specific course for university students: the core lessons that were produced by intra-active (see Barad, 2003, p. 815) and/or assembled (see Latour, 2005) pedagogies. The first lesson I learned from disapproving special education colleagues when I asked them to give a lecture during the course. They told me they did not want to have anything to do with monkeys. The second lesson I learned from my students during the course. One let me know why a live chicken, which she took care of and kept as a pet, was banned from visiting the local kindergarten. Dead chickens were not banned, of course, but served as a meal for the kindergarteners. I explain what these two lessons tell about the ontoepistemological and ethical commitments that affect our educational practices, and I also consider how posthuman pedagogy could enrich the current human-centered education.

This article has an autobiographical tone, which is not entirely uncommon in the context of posthuman philosophy (Gough, 2015; Gough \& Gough, 2017; Herbrechter, 2012). Noel Gough admits in his chapter 'Undoing Anthropocentrism in Educational Inquiry: A Phildickian Space Odyssey?' (2015) that he was inspired by Pinar's (1975) autobiographical method of curriculum inquiry when he began to teach graduate studies in curriculum. Gough uses autobiography in his chapter also because he believes it is 'more informative for readers than a less personal account' (2015, p. 151). Gough refers to William Reid's (1981, p. 168) article in which Reid writes:

When people are asked why they support certain positions and reject others, they usually point to some kind of logical justification. Often, however, this fails to produce an advance in understanding. [--] A deeper question is why people "buy into" particular systems in the first place, and that is, literally, a deeper question, in that the reasons (if indeed it makes sense to speak of "reasons") are hidden even to the individuals concerned.

Because I want to approach this deeper question Reid refers to, I began by telling a personal story about why I ended up dealing with posthuman philosophy. As this article continues, other (anonymous) humans are involved in the story, and they have their own systems they 'buy into.' 
Instead of putting these systems in hierarchical order based on, let's say, their assumed morality, I am more interested in examining the intersections that show how these different systems collide within the context of educational practices.

\section{Lesson One: Why Do Special Education Staff Want to Avoid Monkeys?}

Humans have made lists of the features that separate us from other animals. For instance, language, tool use, rationality, and emotions have been mentioned. In recent decades, the strict divide between humans and nonhuman animals has started to fracture. In academic literature, at least two powerful images portray this fracture. The first is Donna Haraway's (2007, p. 3) question, 'Whom and what do I touch when I touch my dog?' The second is Jacques Derrida (2008, pp. 3-4) feeling ashamed after his cat saw him naked. Both images act as catalysts for a book-length discussion on humans' relationships to others and on the peculiar category of animals, which is a word, as Derrida (2008, p. 31) remarks, humans have given themselves a right to give to live others. Haraway explains in her work A Cyborg Manifesto (2000, p. 293) that 'nothing really convincingly settles the separation of human and animal' and imagines a cyborg, which is a hybrid of machine and animal, hoping that this fictional creation helps break down crucial boundaries, such as human-animal, organismmachine, and physical-nonphysical.

None of those boundaries have certainly broken down yet. When I approached three special education staff members in autumn 2015 and asked them to give a lecture during the course 'Education and Adaptations of Animal Studies,' they declined. One kindly explained to me that sometimes children with disabilities have been compared to monkeys, which is, according to her, really insulting. I did not know how to answer, so I just thanked them for their time and left. This brief meeting, however, taught me that humans and nonhumans are strictly still divided, even (or especially?) by academics, and that nonhuman animals are seen as invariably inferior. They are seen 
as so inferior to humans that even comparing humans to animals is highly insulting. This surprised me, as I had been imagining that at least everybody at the university would have read their Darwin and accepted the animality of the human race. Later, when thinking it through, I started to consider the academic disciplines and realized how deeply the division between humans and nonhumans is rooted in the disciplines as well. History means history of humans; education is about educating humans; in social sciences, the social happens among humans, not between humans and animals or humans and material objects; human medicine is separated from veterinary medicine; and so on. Bruno Latour (2005) has remarked how the strict divisions, which separate humans from objects and animals, between academic disciplines are profoundly political.

It is a relief and a pity to know that this course is not the only animal-related one that has caused a skeptical response among fellow academics. When Clifton Flynn (2003) wanted to organize an undergraduate sociology course called 'Animals and Society' in 2001 at the University of South Carolina Spartanburg, the committee deciding on new courses outlined several concerns. They stated that 'the course was not sociology, the instructor was not qualified in animal behavior, the course was really an "animal rights" course in disguise' (Flynn, 2003, p. 96). Flynn (2003) explained to the committee why the course was a sociology course in its purest forms and how humans can learn about themselves from their attitudes toward, and treatment of, other animals. It seems awkward and petty to think that humans can learn only about the things, emotions, actions, and relations they have with and toward other humans, although so many more beings, organisms, and things exist in our surroundings. Still, the disciplinary boundaries and traditions remain stubbornly there. It is not easy to detach from the humanistic mission that constructs self-worth at the expense of inferior Others, as it is so strongly built in our society and thinking.

The ontological question of the division, or artificial distinction as Palmer et al. (2015, p. 571) state, between humans and other animals is complex. It has roots and manifestations everywhere in human history and culture, for instance, in the philosophy of Kant and Descartes (see 
Steiner, 2011). One influential cultural construction is the Judeo-Christian narrative of God creating a man that has dominance over nature and animals (and women). The right of humans to dominate all other life began with the authorization of an external, metaphysical source, namely, God, but later, the justification was openly based on humans' self-authorization (Bell, 2011, p. 145). The dichotomy between 'rational' humans and 'irrational' animals can be traced back to classical antiquity and has been, predominantly, uncritically reaffirmed in Western philosophy, religion, and science (Steiner, 2011, p. 83; Weisberg, 2011, p. 154). The wish to strictly separate humans from monkeys, as the special education staff expressed their will, therefore, leans on one of the main ontological assumptions of Western (human) thought. The Cartesian dividing system is, according to Zipporah Weisberg (2011, p. 154), constructed on humans' will to repress their own animality.

Two concepts are especially helpful in considering what happened when the special education staff decided that they did not want anything to do with monkeys. The concepts are anthropocentrism and speciesism. Anthropocentrism describes the hierarchical way to think about humans' relationship to nonhuman beings and entities and the belief about humans' 'special, central, even cosmic significance' (Butchvarov, 2015, p. 1). Anthropocentrism, then, is a very accurate concept that describes the attitude of the special education staff. Their reaction reflected a view in which humans are hierarchically situated far above other animals, and a comparison between the two species is insulting. 'Monkey' can also, in our culture, be used as a pejorative. It is not the only animal epithet that has that type of use in Western culture: For instance, rat, pig, and hyena are used as insults. In addition, in [language] the word [word], which is a slang word for an animal, is used for shaming purposes. It is used to describe a human who behaves in a vulgar manner, for instance, is drunk and acts rude. The fact that the special education staff felt that comparing children with disabilities with monkeys is an insult may arise from a situation in which the comparison was meant to be an insult in the first place. The animal epithets that are used as pejoratives are indications of anthropocentrism rooted in Western culture. 
Within the social sciences and humanities, there has been much criticism of racism, classism, and (hetero)sexism, but the critical reflection of speciesism is not as common. The framework of speciesism enables systemic discrimination against others based on species (Wolfe, 2003). Speciesism can be defined as "prejudice or attitude of bias in favor of the interests of members of one's own species and against those of members of other species' (Singer, 1995, p. 6). Speciesism can be seen also as one form of anthropocentrism (Milligan, 2011, p. 223). Related to speciesism, which Cary Wolfe (2003, p. 101) sees as a logical and linguistic structure that marginalizes and objectifies the other and as material practices that reproduce that logic, Wolfe presents four categories. They are animalized animals, humanized animals (primarily pets), animalized humans, and humanized humans (Wolfe, 2003, p. 101). The category of animalized humans is the one that resonates with the image of a child with disabilities compared to a monkey, the image that the special education staff had in mind when they refused to give a lecture on education and animal studies. For Wolfe (2003, p. 101), this category is 'perhaps the most troubling category of all, since all manner of brutalizations carried out by cultural prescription can serve to animalize humans.' It is a distressing and frightening category. It is worth keeping in mind that humans mass murder animals constantly, and the justification for that is the animality of the latter. ${ }^{3}$ The animalized child with disabilities, which the special education staff recalled, belongs to this upsetting category that evokes fear in us.

What is particularly interesting here is that monkeys are among the species that are closest to humans genetically; humans and monkeys are primates. Monkeys are our closest relatives. They mirror us. They remind us of us. Therefore, they are also the most threatening species for humans to think about and to interact with, if the main goal is to maintain the strict division that separates humans from other species. The rejective attitude toward the comparison between children with

\footnotetext{
${ }^{3}$ Othering animals or positioning them below humans usually legitimizes the use of them as food or commodities for humans. In legislation, animals are not individual subjects or merely objects, that is, the property of humans, but something in between.
} 
disabilities and monkeys is logical in this sense: The comparison is just too ominous. To what changes would it lead in our society if we admitted that other species are not less valuable than us? What kind of guilt would we have to deal with?

If the comparison between children with disabilities and monkeys is allowed, it facilitates some enlightening approaches. For instance, Sue Donaldson and Will Kymlicka (2016) remarked how citizenship is based on linguistic agency and suggested that rethinking citizenship would help citizens with no linguistic skills, that is, young children, animals, and humans with cognitive disabilities, participate in society. In addition, Helene Pedersen (2015) focused on the subordinate groups of humans and animals that have been silenced in our 'democratic' society. According to Pedersen (2015, p. 65), animals are allowed to be present in (human) neighborhoods as long as the animals remain mute and speechless. However, an increasing number of qualitative inquiries are paying attention to the ways by which mute citizens can be heard. For instance, within anthropology, Palmer et al. (2015) studied orangutans' perspectives on relationships with other orangutans and humans. It is almost too obvious that if the barrier between humans and other animals disappeared, at least four research areas (animal studies, disability studies, special education, and studies on babies) would benefit. The methods and policies that would allow those who cannot use human language to participate in society and to express their thoughts could be applied to various situations with various subjects. Unfortunately, the barrier exists, and dialogue between the four research areas is largely lacking.

\section{Lesson Two: Why Is a Live Chicken Banned from the Kindergarten?}

Although the special education staff refused to be involved, the course on education and animal studies began with other open-minded and curious lecturers. The topics included, for instance, 
animals' embodiment, language, play, and agency. During one of my lectures, we were talking about working animals, especially animals used in humans' therapeutic processes. A student of early childhood education wanted to give an example and stated that in her spare time she takes care of abandoned chickens. After reading news coverage about a Finnish therapy chicken, she decided to see if one of her chickens would enjoy that kind of work. She, as a future kindergarten teacher, contacted a local kindergarten and asked if she and her chicken could visit the children. At first, the staff was delighted, but soon after, they cancelled the visit. They explained to the student that they are worried that the children might start asking questions. They expected the unwanted questions, because dead chickens were often served as a meal in the kindergarten, and the food was called 'chicken': the same word for a live chicken. The live chicken, consequently, was banned from the kindergarten.

This brings us to the topic of animal bodies and their presence or absence in pedagogical institutions and practices. Alyce Miller (2015, p. 105) has written a thought-provoking article on the pedagogical challenge of 'keeping the animal body in our sight.' Miller (2015, p. 109) stated that often when a subject becomes an interest of academics, the subject itself seems to disappear and turn into an object produced via writing. Miller herself organized an interdisciplinary course called 'Animals and Ethics' at Indiana University and decided to bring animals into the classroom, with a carefully erected intellectual framework, of course. During the course, visitors included ex-fighting dog Fred and yellow ball python Lucille (Miller, 2015).

The course that I organized is not that kind of a success story when it comes to bringing animal bodies in sight. Our university policies forbid animals on the university campus. Before the implementation of this specific course on education and animal studies, I had just argued with the superintendent about attaching some pictures temporarily to a wall on campus. The reason for that request was that we had child visitors in another course, and the students wanted to organize a picture navigation game for them. I lost that battle, so I knew that I had no hope of getting 
permission to bring in live animal visitors. Dead animals are present on the university campus all the time, though, because on the ground floor there is a cafeteria that specializes in vegetarian food but still serves dead animals.

The kindergarten did not want to have a live chicken for a visit nor did our university. Live animal bodies were present only in our discourses, in our imagination, and as representations in pictures and videos. The pedagogical challenge of keeping animal bodies in sight (Miller, 2015) proved to be a real challenge. Dead bodies of animals were warmly welcomed into educational institutions while live ones were not. What kind of pedagogy is that, and what kind of values does it espouse? It felt as if Karen Davis' (2011, p. 38) statement once again had proved itself true: 'Animals are physically altered, rhetorically disfigured, and ontologically obliterated to mirror and model the goals of their exploiters.' The most worrying part of the whole process was, to me, the argument presented by the staff of the local kindergarten. They did not want the live chicken because 'children could start asking questions.' It may be an idealistic thought, but I imagined that one of the goals of education, in general, is to get participants to ask questions and to think for themselves. This episode shows the opposite: Children's possible questions were seen as a threat.

The history of education and the history of children's culture (controlled by adults) is full of examples of issues that have remained silenced. For instance, after World War I portrayals of war were lacking in children's literature. It was as if they were too horrible to describe, and another threat was that this kind of description could have shown adults to be irresponsible and not in control of the situation (Hunt, 2001, p. 304). The discussion of humans mass-murdering chickens, after raising them in horrifying conditions, is a topic that kindergarten teachers likely do not want to bring up. The ethical questions may be just too difficult, and the example displayed by current adults is not necessarily morally sustainable. Kindergarten teachers probably have not had much training concerning how to deal with these kinds of issues with children which leads to insecurity about encountering the issues. There may also be a practical side involved: If some children do not 
want to eat meat after realizing where it comes from, it might be too arduous for adults to organize a vegetarian diet for them. However, this kind of attitude tells us something about current education. Is it so that if education and growing up bring children from 'nature' toward 'reason' and from 'freedom' toward 'culture' (see Kennedy, 2006, p. 121), the direction might not be exactly ideal? Might there be something wrong in this anthropocentric construction of a rational and cultural human being, a celebrated outcome of our valuable, human-centered educational system? As Nathan Snaza (2015, p. 21) has put it, within 'humanizing' education and educational institutions, "humans pass over in silence the extraordinary violence "humans" do to animals, ecosystems, to whole species, and, of course, to each other.'

I cannot help but imagine that a dog would have been allowed to visit the kindergarten while the chicken was not. It would have been easier, because in [country] humans do not eat dogs, not usually or publicly at least. Different species have very different statuses in our society. In Western societies, many dogs and cats are seen as family members, and many humans even describe dogs and cats as their children, babyfy them, and dress them like children (Power, 2008; Vänskä, 2014). Chickens, however, are rarely kept as companions, family members, or pets. Chickens have had five thousand years of domestic arrangements with humans, and in 2000, ten billion chickens were slaughtered daily in the United States alone (Haraway, 2007, p. 266). Although a dog may get a pet funeral including a coffin, prayers, a memorial tablet, and a temple altar (Collier, 2016, p. 6), most dying chickens remain anonymous and invisible. The only visible part of their death is the end result, the corpse, as it lies on the shelf in supermarket or on our plate. Donna Haraway (2007, p. 265) stated that a chicken is no coward: It may be anxious while fearing that the sky may fall, but the chicken also has a history as a fighting cock and a history of being genetically manipulated since the 1950s. Thus, chickens know a lot about human-led capitalism and eugenics, too.

\section{Conclusion}


Pedagogies produce and construct all kinds of impressions, conceptions, and value structures. They reflect us, and they affect us. After two lessons learned, one concerning humans' desperate need to separate themselves from monkeys and another concerning humans' educational practices that ignore the suffering of other animals, it becomes clear that the presence of other species in our pedagogical practices could be thought-provoking, even essential. The presence of other species helps humans challenge the humanist mind-sets of humans' superiority to other animals and expose these mind-sets as being more ideology than reality (Sanza \& Weaver, 2015, p. 2). The presence of Others helps us ask questions. The threat of ecological disaster has made us think of a more-thanhuman world and a call for education that cultivates posthuman sensibilities (Le Grange, 2017), that fundamentally challenges all preconceived categories of thought (Wallin, 2017), that cherishes zoontology, zoöepistomology, and zooliteracy (Pedersen, 2015), and that is not driven by exploitation, dehumanization, and asymmetrical violence (Snaza \& Weaver, 2015). Although the foundations of international educational policy making are anthropocentric and exclusionary (Pedersen, 2015, p. 70), there is still hope that someday a live chicken will be invited to pedagogical institutions and confronted. Weaver (2015, p. 186) hopefully declared: 'Through human memory and animal forgetfulness [of humans], our cultivation begins.'

The two lessons dealt with here also raise an unavoidable and vital question of ethics in human-animal relationality. The binary arrangement between right and wrong is present in the treatment of-or avoidance of-Others in pedagogical situations. The anonymous chicken and the metaphorical monkey presented here may be seen as one kind of uneasy assemblage, but not as disturbing or provoking as the one that Jane Bone and Mindy Blaise (2015) presented in their article concerning posthuman packaging. They created a picture of packaged and processed beings by combining the stories of imprisoned, asylum-seeking children and live exported animals to 'form something that disturbs the usual elements that contribute to early childhood field' (Bone \& Blaise, 
2015, p. 25). Bone and Blaise, too, were concerned that issues that seem too hard and tense get shut out of pedagogical practices. Researchers have suggested that praxis of care and response, that is, response-ability (Haraway, 2016) and posthuman relational ethics (Bone \& Blaise, 2015), could evoke discussion of the complex relationships humans share with other species on this planet.

Educational practices, pedagogies, and ethics are not the only ones in need of reconceptualization in the aftermath of posthuman thinking. Educational research might also benefit from transformation. Traditional qualitative inquiry, as well as quantitative, is dominated by a subject-object hierarchy that creates methodocentrism in which researchers' faithfulness to a method becomes the main concern while the real interactions and intra-actions of human and nonhuman participants are removed from the researchers' work (Sanza \& Weaver, 2015; Weaver \& Snaza, 2017). Posthuman thinking challenges the artificial disciplinary boundaries and politics behind them; it challenges those who are used to focusing on human(i)s(m) to turn their gaze toward other beings and things as well. 'Humans are not without all these Others: These nonhuman Others are not here for us to "use,"” remind Snaza and Weaver $(2015$, p. 8). The majority of the posthuman research on the relationship between animals and humans has been theoretical, and the need to engage with empirical material has been announced (Fox, 2006, p. 526). This is a compelling invitation to the educational research community. The research may involve monkeys or chickens, dead or alive, but in any case, it could make us think and ask more questions. As I see it, well-set questions are (or at least could be, if they are not suppressed because of fear) the foundation of philosophy and education, the two sublime projects of human animals. 


\section{References}

Abell, J. (2013). Volunteering to help conserve endangered species: An identity approach to humananimal relationships. Journal of Community \& Applied Social Psychology, 23, 157-170.

Amiot, C. E., \& Bastian, B. (2015). Toward a psychology of human-animal relations. Psychological Bulletin, 141(1), 6-47.

Barad, K. (2003). Posthumanist performativity: Toward an understanding of how matter comes to matter. Signs: Journal of Women in Culture and Society, 28(3), 801-831.

Bell, A. (2011). The dialectic of anthropocentrism. In J. Sanbonmatsu (Ed.), Critical theory and animal liberation (pp. 144-153). Lanham, MA: Rowman and Littlefield.

Bone, J., \& Blaise, M. (2015). An uneasy assemblage: Prisoners, animals, asylum-seeking children and posthuman packaging. Contemporary Issues in Early Childhood, 16(1), 18-31.

Braitman, L. (2014). Animal madness: How anxious dogs, compulsive parrots, and elephants in recovery help us understand ourselves. New York, NY: Simon \& Schuster.

Butchvarov, P. (2015). Anthropocentrism in philosophy: Realism, antirealism, semirealism. Boston, MA: De Gruyter.

Chiew, F. (2016). A posthuman pedagogy with Rancière and Bateson. E-publication ahead of print. Critical Studies in Education, 59(3), 297-312.

Collier, I. D. (2016). More than a bag of bones: A history of animal burials. In M. DeMello (Ed.), Mourning animals: Rituals and practices surrounding animal death (pp. 3-10). East Lansing: Michigan State University Press.

Davis, K. (2011). Procrustean solutions to animal identity and welfare problems. In J. Sanbonmatsu (Ed.), Critical theory and animal liberation (pp. 38-53). Lanham, MD: Rowman and Littlefield. 
DeLoache, J. S., Pickard, M. B., \& LoBue, V. (2011). How very young children think about animals. In P. McCardle, S. McCune, J. A. Griffin, \& V. Maholmes (Eds.), How animals affect us: Examining the influences of human-animal interaction on child development and human health (pp. 85-99). Washington, DC: American Psychological Association.

Derrida, J. (2008). The animal that therefore I am (M.-L. Mallet, Ed.). New York, NY: Fordham University Press.

Donaldson, S., \& Kymlicka, W. (2016). Rethinking membership and participation in an inclusive democracy. In B. Arneil \& N. Hirschmann (Eds.), Disability and political theory (pp. 168197). Cambridge, England: Cambridge University Press.

Ferrando, F. (2013). Posthumanism, transhumanism, antihumanism, metahumanism, and new materialism: Differences and relations. Existenz: An International Journal in Philosophy, Religion, Politics, and the Arts, 8(2), 26-32.

Flynn, C. P. (2003). A course is a course, of course, of course (unless it's an animals and society course): Challenging boundaries in academia. International Journal of Sociology and Social Policy, 23(3), 94-108.

Fox, R. (2006). Animal behaviours, post-human lives: Everyday negotiations of the animal-human divide in pet-keeping. Social \& Cultural Geography, 7(4), 525-537.

Gough, N. (2015). Undoing anthropocentrism in educational inquiry: A phildickian space odyssey? In N. Snaza \& J. A. Weaver (Eds.), Routledge International Studies in the Philosophy of Education. Posthumanism and educational research (pp. 151-166). New York, NY: Routledge.

Gough, A., \& Gough, N. (2017). Beyond cyborg subjectivities: Becoming-posthumanist educational researchers. Educational Philosophy and Theory, 49(11), 1112-1124.

Grusin, R. (2015). Introduction. In R. Grusin (Ed.), The nonhuman turn (pp. vii-xxix). Minneapolis: University of Minnesota Press. 
Haraway, D. (2000). A cyborg manifesto: Science, technology and socialist-feminism in the late twentieth century. In D. Bell \& B. M. Kennedy (Eds.), The cyberculture reader (pp. 291324). London, England: Routledge.

Haraway, D. (2007). Posthumanities Series: Vol. 3. When species meet. Minneapolis: University of Minnesota Press.

Haraway, D. (2016). Experimental Futures: Technological Lives, Scientific Arts, Anthropological Voices Series. Staying with the trouble: Making kin in the Chthulucene. Durham, NC: Duke University Press.

Herbrechter, S. (2012). Posthumanism, subjectivity, autobiography. Subjectivity, 5(3), 327-347.

Hunt, P. (2001). Children's literature. Malden, MA: Blackwell.

Kazdin, A. E. (2011). Establishing the effectiveness of animal-assisted therapies: Methodological standards, issues, and strategies. In P. McCardle, S. McCune, J. A. Griffin, \& V. Maholmes (Eds.), How animals affect us: Examining the influences of human-animal interaction on child development and human health (pp. 35-51). Washington, DC: American Psychological Association.

Kennedy, D. (2006). Changing conceptions of the child from the Renaissance to post-modernity. Lewiston, NY: Mellen Press.

Latour, B. (2005). Reassembling the social: An introduction to actor-network-theory. Oxford, England: Oxford University Press.

Le Grange, L. (2017). Spinoza, deep ecology and education informed by a (post)human sensibility. Educational Philosophy and Theory, 50(9), 878-887.

Milligan, T. (2011). Speciesism as a variety of anthropocentrism. In R. Boddice (Ed.), Anthropocentrism: Humans, animals, environments (pp. 223-244). Leiden, Germany: Brill. 
Miller, A. (2015). Losing animals: Ethics and care in a pedagogy of recovery. In N. Snaza \& J. A. Weaver (Eds.), Posthumanism and educational research (pp. 104-118). New York, NY: Routledge.

Mustola, M. (2018). Children's Play and Art Practices with Agentic Objects. In C. Schulte \& C. M. Thompson (Eds.) Communities of practice: Art, play, and aesthetics in early childhood (pp.117-131). London: Springer.

Palmer, A., Malone, N., \& Park, J. (2015). Accessing orangutans’ perspectives: Interdisciplinary methods at the human/animal interface. Current Anthropology, 56(4), 571-578.

Pedersen, H. (2015). Education policy making for social change: A posthumanist intervention. In N. Snaza \& J. A. Weaver (Eds.), Posthumanism and educational research (pp. 56-75). New York, NY: Routledge.

Pinar, W. F. (1975). Currere: Towards reconceptualization. In W. F. Pinar (Ed.), Curriculum theorizing: The reconceptualists (pp. 396-414). Berkeley, CA: McCutchan.

Power, E. (2008). Furry families: Making a human-dog family through home. Social \& Cultural Geography, 9(5), 535-555.

Rautio, P. (2013). Children who carry stones in their pockets: On autotelic material practices in everyday life. Children's Geographies, 11(4), 394-408.

Reid, W. A. (1981). The deliberative approach to the study of the curriculum and its relation to critical pluralism. In M. Lawn \& L. Barton (Eds.), Rethinking curriculum studies (pp. 160187). London, England: Croom Helm.

Singer, P. (1995). Animal liberation. London, England: Pimlico.

Snaza, N. (2015). Toward a genealogy of educational humanism. In N. Snaza \& J. A. Weaver (Eds.), Posthumanism and educational research (pp. 17-29). New York, NY: Routledge. 
Snaza, N., \& Weaver, J. A. (2015). Introduction: Education and the posthuman turn. In N. Snaza \& J. A. Weaver (Eds.), Posthumanism and educational research (pp. 1-14). New York, NY: Routledge.

Steiner. G. (2011). Toward a non-anthropocentric cosmopolitanism. In R. Boddice (Ed.), Anthropocentrism: Humans, animals, environments (pp. 81-114). Leiden, Germany: Brill.

Vänskä, A. (2014). New kids on the mall: Babyfied dogs as fashionable co-consumers. Young Consumers, 15(3), 263-272.

Wallin, J. J. (2017). Pedagogy at the brink of the post-Anthropocene. Educational Philosophy and Theory, 49(11), 1099-1111.

Weaver, J. A. (2015). To what future do the posthuman and posthumanism (re)turn us; Meanwhile how do I tame the lingering effects of humanism? In N. Snaza \& J. A. Weaver (Eds.), Posthumanism and educational research (pp. 182-194). New York, NY: Routledge.

Weaver, J. A., \& Snaza N. (2017). Against methodocentrism in educational research. Educational Philosophy and Theory, 49(11), 1055-1065.

Weisberg, Z. (2011). Animal repression: Speciesism as pathology. In J. Sanbonmatsu (Ed.), Critical theory and animal liberation (pp. 154-170). Lanham, MD: Rowman and Littlefield.

Wirman, H. (2014). Games for/with strangers: Captive orangutan (Pongo pygmaeus) touch screen play. Antennae: The Journal of Nature in Visual Culture, 30, 103-113.

Wolfe, C. (2003). Animal rites: American culture, the discourse of species, and posthumanist theory. Chicago, IL: The University of Chicago Press.

Wolfe, C. (2009). What is posthumanism? Minneapolis: University of Minnesota Press.

Wynne, C. D. L., Dorey, N. R., \& Udell, M. A. R. (2011). The other side of the bond: Domestic dogs' human-like behaviors. In P. McCardle, S. McCune, J. A. Griffin, \& V. Maholmes (Eds.), How animals affect us: Examining the influences of human-animal interaction on child 
development and human health (pp. 101-115). Washington, DC: American Psychological Association. 